\title{
4 \\ Do farmers love brolgas, seagrass and coral reefs? It depends on who's paying, how much, and for how long!
}

\section{Geoff Park}

\section{Key lessons}

- Productive farming can work hand in hand with environmental protection, especially when it is supported through understanding of farm-scale realities - such as a better understanding of the costs and risks associated with practice change - and better integration of biophysical, economic, and social knowledge.

- There needs to be better recognition of the extent to which improved private land management contributes to public good outcomes.

- The voluntary adoption of best management practices (BMPs) is unlikely to go far towards achievement of SMART environmental goals, as most required practices are simply not profitable or adoptable at the scale required.

- Successful outcomes will rely on the establishment of longterm financial incentives, in the form of stewardship payments to farmers, for the protection of important environmental assets. 
- Evaluation of the ecological, social and economic implications of SMART targets is a critical step in understanding their attainability and desirability.

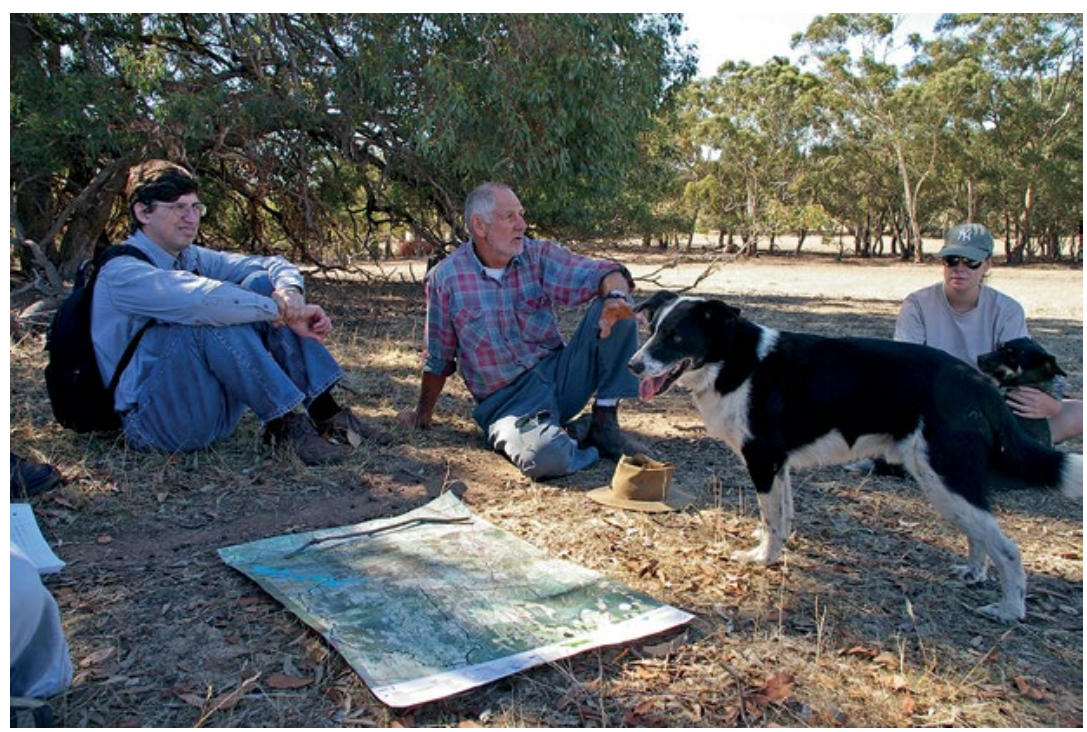

Figure 4.1: Farmers are better able to engage with environmental protection on their land where such work takes into account farm-scale realities.

Source: Photo by Geoff Park.

When it comes to farming and the environment, the rhetoric (some would say hyperbole) is full of claims about win-win outcomes. The truth, however, is less straightforward, and often not so convenient.

This chapter will reflect on this notion of win-win by examining the relationship between land management practices and the protection of significant environmental assets: natural assets of importance to the wider Australian community. Three case studies are provided, which are connected by a common thread: achieving significant and enduring environmental outcomes can only be contemplated if the public and private benefits (Pannell 2008) of land use and land management change are analysed and understood. 
The first case study is set in the volcanic plains of central Victoria, the second in the catchment of Corner Inlet in Gippsland (south east Victoria), and the third lies northwards in the beef and sugar cane country that drains to the southern extremity of the Great Barrier Reef. Each case study spans dimensions of investment planning, strategic planning, and implementation. A feature of all three is the establishment of SMART targets that have been used to guide the design and evaluation of projects and plans. In all three case studies, an assessment was made using INFFER, the Investment Framework for Environmental Resources (Pannell et al. 2011, and see Box 4.1), to assess the cost-effectiveness of different scenarios, and to support the choice of appropriate actions and policy interventions. This was crucial, particularly in understanding the nature and scale of actions required by private landholders, the private costs associated with adopting these actions, and the technical feasibility and risks involved in generating the predicted environmental benefits.

What are SMART targets? There is some variation in how the letters of this acronym are defined. Our definition is widely used and simply asks if a target is Specific, Measurable, Attainable, Relevant, and Time-bound? The importance of SMART targets has been explicitly recognised by governments (Australian Government 2014).

Specific: The goal is described in a precise and unambiguous way.

Measurable: The goal definition is based on a variable which can be monitored and recorded reliably without unreasonable expense.

Attainable: A goal is more likely to be attainable when you plan your steps wisely and establish a time frame that allows you to carry out those steps. Thinking about attainable and realistic goals at the same time is useful.

Realistic: To be realistic, a goal must represent an objective toward which everyone is willing and able to work. A goal can be both high and realistic; the goal should represent substantial progress.

Time-bound: A particular date is provided by which time the goal will have been achieved. The time frame for the goal can be of any relevant duration. The time frame of achieving goals is related to the time for reasonable ecosystem response and costs. 
The development and specification of SMART goals is crucial to understanding and analysing the costs and benefits of any proposed project (Doran 1981; McDonald and Roberts 2006). As a side note, I led a recent analysis that found that the use of SMART goals in planning by Australian regional natural resource management (NRM) bodies is not widespread and, in some cases, is getting worse (Park et al. 2013). Table 4.1 details the SMART goals that form the three case studies examined in this chapter.

Table 4.1: Summary of SMART goals respective case studies.

\begin{tabular}{|c|c|}
\hline Case study & SMART goals \\
\hline Moolort wetlands & $\begin{array}{l}\text { By } 2015 \text { to: } \\
\text { - Increase the extent of native vegetation surrounding the } \\
\text { - } \quad \text { Impromps on private land by } 150 \text { ha from } 1,034 \text { ha to } 1,184 \text { ha. } \\
\text { swamps on private land by } 10 \text { per cent (as measured by } \\
\text { appropriate habitat assessment metric). }\end{array}$ \\
\hline Corner Inlet & $\begin{array}{l}\text { By 2032, reduce sediment and nutrient loads to: } \\
\text { - } \quad \text { Corner Inlet - nitrogen by } 15 \text { per cent, phosphorus by } \\
15 \text { per cent, and suspended sediment by } 10 \text { per cent. } \\
\text { - } \quad \text { Nooramunga - nitrogen by } 10 \text { per cent, phosphorus by } \\
10 \text { per cent, and suspended sediment by } 15 \text { per cent. }\end{array}$ \\
\hline $\begin{array}{l}\text { Great Barrier Reef } \\
\text { and Great Sandy } \\
\text { Straits - Burnett- } \\
\text { Mary region }\end{array}$ & $\begin{array}{l}\text { By } 2033, \text { to achieve: } \\
\text { - } 20 \text { per cent overall reduction in anthropogenic suspended } \\
\text { - } \quad 20 \text { per cent in anthropogenic loads of particulate nitrogen } \\
\text { (PN) and particulate phosphorus (PP). } \\
\text { - } 50 \text { per cent reduction in anthropogenic loads of dissolved } \\
\text { inorganic nitrogen (DIN). } \\
\text { - } 50 \text { per cent reduction in anthropogenic loads of dissolved } \\
\text { inorganic phosphorus (DIP). } \\
\text { - } 60 \text { per cent reductions of loads of PSIl herbicides } \\
\text { (hexazinone, ametryn, atrazine, diuron and tebuthiuron). }\end{array}$ \\
\hline
\end{tabular}

\section{The Moolort Plains}

The Moolort Plains consists of a chain of approximately 50 wetlands in the Loddon catchment, north central Victoria. The catchment of these wetlands is on the Victorian Volcanic Plain, and is Victoria's only national biodiversity hotspot (Australian Government 2015). The wetlands consist of freshwater meadows, shallow freshwater marshes, and deep freshwater marshes. No two wetlands in the network are the same; they vary in size (ranging from 1-2 ha to more than 200 ha in size), shape, and flora. These wetlands provide a range 
of breeding, roosting, and nesting sites for native fauna species, and are located in a largely cleared and fragmented landscape. A number of the wetlands are lignum dominated, providing excellent habitat for nesting waterbirds, including brolga.

The wetlands occur within the farm area, as islands of biodiversity, amongst intensive grazing and cropping systems. At the commencement of the project, few of the wetlands were fenced, with most grazed regularly or on an occasional basis. A number of the wetlands have been cropped in the past, and the possibility of future cropping is ever present. While many of the farmers who own these areas are driven, at least in part, by conservation values, the wetlands are seen as part of the farm production system, providing valuable fodder for animals, especially in times of drought, or as potential cropping land.

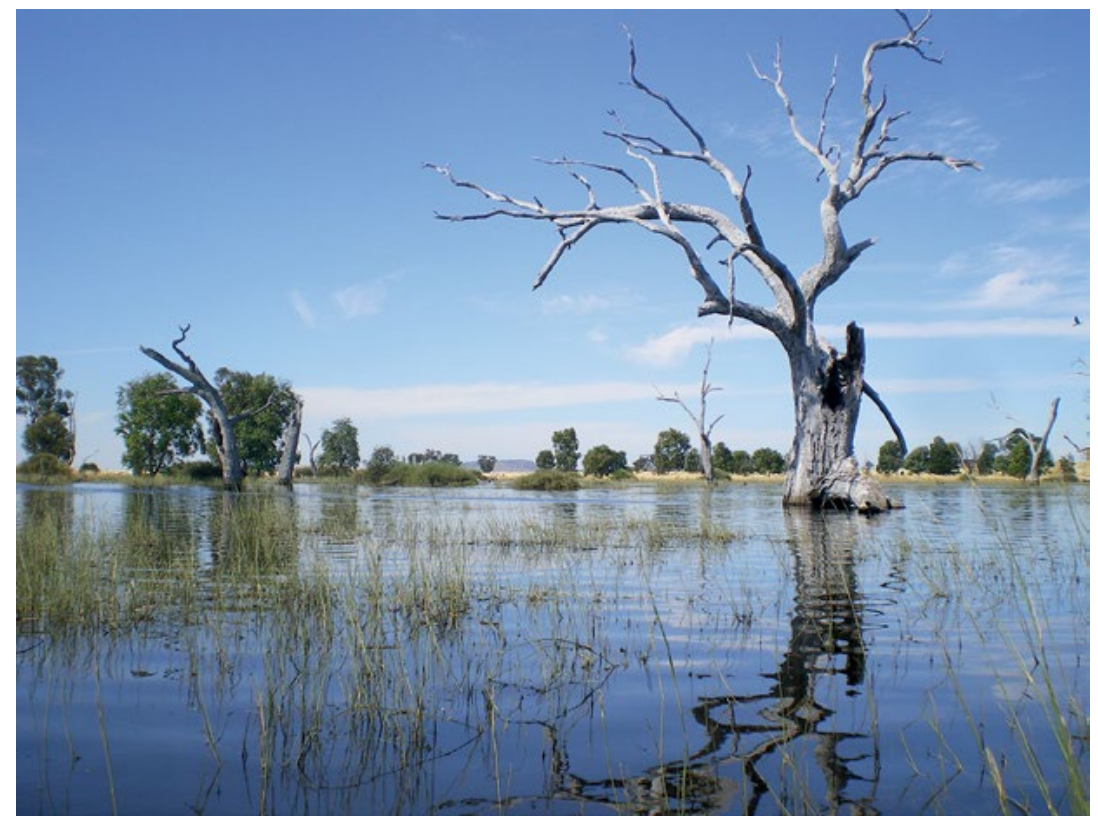

Figure 4.2: Frogmore Swamp is a wildlife refuge on the Moolort Plains.

Source: Photo by Geoff Park.

Preliminary discussions with the relevant landholders indicated that if projects demanding permanent changes in land use (e.g. cessation of grazing and cropping) and/or land management (e.g. fencing and changed grazing regimes) were to be successful, then landholders 
would need to be compensated for losses in production. This would require an appreciation of the economic production value of these areas before landholders would enter into agreements aimed at securing long-term conservation outcomes. On this basis, farm-scale economic assessments were undertaken to inform the design of a system of stewardship payments, tied to the establishment of conservation covenants.

As a result, some 400 hectares of significant wetland has been secured with permanent conservation covenants through the implementation of a project funded by the Australian Government. The level of funding (provided over a two-year period as works were implemented) through landholder stewardship agreements has been significant (on a per hectare basis), approaching current land values. Without this level of funding, it is doubtful that the project objectives would have been even partially achieved.

The remaining two case studies represent strategic planning projects for water quality, designed to inform future investment and implementation activities at sub-regional and regional scales.

\section{Corner Inlet}

Situated in south eastern Victoria, the Corner Inlet catchment is approximately $2,300 \mathrm{~km}^{2}$ in size and stretches along the South Gippsland coastline from Woodside to Wilsons Promontory. It is a highly productive area, supporting dairy, beef, and mixed grazing enterprises, and significant areas of production forestry. The region supports a significant Victorian commercial bay and inlet fishery, including 18 licensed commercial fishers. Corner Inlet itself supports outstanding environmental values that have been recognised through its listing as a wetland of international importance under the Ramsar Convention. The Ramsar area within Corner Inlet is the most southerly marine embayment and tidal mudflat system of mainland Australia, with extensive areas of seagrass supporting key ecological, economic, and social values. 


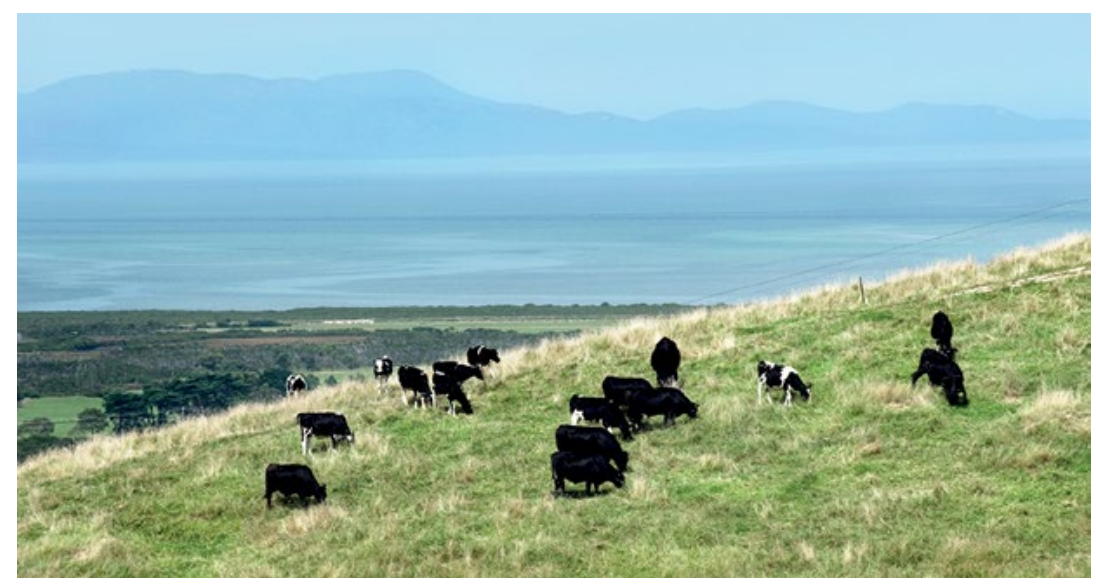

Figure 4.3: Cows grazing in the Corner Inlet, near Wilsons Promontory, Gippsland, Victoria.

Source: Photo by Geoff Park.

Improvement of water quality in Corner Inlet requires a range of land management changes on farming lands, associated with the adoption of BMPs (e.g. maintaining ground cover and direct works, such as riparian fencing and revegetation) on agricultural land. Extension, positive incentives, and regulation compliance activities have all been used in Corner Inlet.

For activities on agricultural land aimed at improving water quality, most programs have been focused on incentive and extension activities to influence the implementation of actions and the adoption of BMPs. Some of these programs operate in tandem; for example, extension activities often identify on-ground works, such as waterway fencing, which are then implemented through direct grant programs. Likewise, incentive delivery is generally coupled with extension information for landholders outlining appropriate maintenance activities. Historically, these programs have been successful in engaging landholders in the implementation of actions and the adoption of BMPs, and have been delivered in a collaborative way across agencies.

Initially, in the development of the Corner Inlet Water Quality Improvement Plan (WQIP) (Dickson et al. 2013), a set of aspirational targets were analysed. These targets, requiring significant reductions in the load of phosphorus (30 per cent), nitrogen (30 per cent) and sediment (10 per cent), were deemed to be crucial to protect the ecological values of the area. 
However, bio-economic modelling results indicated (Dickson et al. 2013) that while these targets were theoretically feasible, they would require large-scale changes in land use (e.g. conversion of grazing land to native vegetation), together with long-term stewardship payments to support landholder adoption of BMPs. Not only would the cost of these changes have been very large (in the order of $\$ 35$ million annually) they would have invoked unacceptable socio-political risks, such as those associated with conversion of marginal farm land into permanent conservation areas. Consequently, a set of more modest SMART targets were used (see Table 4.1) to inform the future implementation of works to protect water quality in Corner Inlet. These targets could be reached without land use change, but still require ongoing payments for BMP adoption, together with significant waterway and erosion works.

The degree to which these modest targets will support a significant ecological response (e.g. an increase in the extent and condition of seagrass) remains a matter of conjecture, as the science regarding ecologically relevant targets for Corner Inlet is equivocal (Dickson et al. 2013).

What is clear is that the level of funding available through current programs (approximately $\$ 1$ million annually) is not sufficient to achieve the required reduction in nutrient and sediment entering Corner Inlet, and that a scaled-up program (in the order of $\$ 4$ million annually) is required to meet the modest, but agreed, implementation targets that form the basis of the WQIP. This is not surprising given the findings of analyses for similar environments, such as the Gippsland Lakes, where it has been estimated that a 40 per cent reduction in phosphorus entering the system would require around $\$ 1$ billion over 25 years (Roberts et al. 2012), well beyond the current levels of funding available for catchment scale works.

\section{The Great Barrier Reef and Great Sandy Straits}

The Great Barrier Reef and Great Sandy Straits areas are located adjacent to the Burnett-Mary NRM region, in southern Queensland. The Burnett-Mary region contains a diverse range of riverine, coastal, and marine habitats. Included in the region is the southernmost 
portion of the World Heritage-listed Great Barrier Reef Marine Park, and the Ramsar-listed Great Sandy Strait, which host biodiversity values that are globally important, including important populations of threatened dugong.

The Burnett-Mary region has an approximate catchment area of $56,000 \mathrm{~km}^{2}$ and is approximately 12 per cent of the total Great Barrier Reef catchment area $\left(423,122 \mathrm{~km}^{2}\right)$. The health of the marine environment is affected by a range of short-term and chronic longer term threats. The major pressures and threats include terrestrial pollutants (sediment, nutrients and pesticides), coastal development, shipping (and boating), fishing/netting, and climate change. Collectively, terrestrial runoff (and resulting pollutant loads and poor water quality) is considered to have the most effect on coastal and marine assets in the region.

The experience in the Burnett-Mary region has a number of parallels with Corner Inlet. In the development of the Burnett-Mary WQIP, an initial set of ecologically relevant targets were set for nutrients, sediments, and pesticides. Again, the cost and feasibility of achieving these targets was assessed using a bio-economic model, with the results suggesting an annual investment of $\$ 16$ million would be required to support BMP adoption in the sugar cane and grazing industries. While not requiring land use change, as was the case for Corner Inlet, this result was deemed to be unrealistic, given current and likely future levels of funding. Consequently, a set of revised SMART targets (see Table 4.1), based on the Reef Plan Water Quality Protection Plan (Secretariat for Reef Water Quality Protection 2013), were used to underpin the WQIP. Reaching these targets is still challenging, with an annual investment of $\$ 5$ million, and would require a targeted approach to BMP support, largely involving the sugar cane industry rather than grazing, and with areas of specific geographic focus.

As with Corner Inlet, the extent to which the agreed targets would protect the key ecological values of the Great Barrier Reef and Great Sandy Straits requires further research. 


\section{Box 4.1: INFFER - Investment Framework for Environmental Resources}

INFFER ${ }^{\mathrm{TM}}$ is a tool for developing and prioritising projects to address environmental issues such as reduced water quality, biodiversity, environmental pests, and land degradation. It is designed to help environmental managers achieve the most valuable environmental outcomes with the available resources.

It consists of a seven-step process, which begins by identifying significant assets and works through project development, project assessment and selection, implementation, and, finally, monitoring, evaluation, and adaptive management. (For the logic behind these steps, see Chapter 22, in which David Pannell reflects on the how the performance of agri-environment programs can be improved.)

The Project Assessment Form, completed in step three, is the key component of the process. This is where users record information about the asset, the threats compromising it, the goals that the project will achieve, and the actions needed to achieve those goals. Judgements about the likelihood of success in terms of technical feasibility and community and government support are also made and recorded here, and the proposed project budget is specified. The core information is used to calculate a benefit-cost ratio that indicates the project's value for money.

\section{Step 1: Identifying significant assets}

A list of significant natural assets that are candidates for investment is prepared. These assets can be drawn from existing documents or lists, from community workshops, from relevant experts, or from analytical processes, such as systematic conservation planning. At the regional level, the list may include 100 to 300 significant assets.

\section{Step 2: Filtering significant assets}

Using a simplified set of criteria, the list of significant assets is filtered down to 20-40 assets. Our suggested approach is to identify assets of high significance, with high current or predicted future damage. The filtered list is further reduced (to 10-20) using the five questions on the INFFER pre-assessment checklist. Assets may be culled at this point because they are not spatially explicit, because a specific, measurable, time-bound goal cannot be formulated, or because an initial assessment indicates that the project would not be cost-effective.

\section{Step 3: The Project Assessment Form}

Using the INFFER Project Assessment Form, develop an internally consistent project for each asset on the reduced list. This process draws together readily available information, consisting of desktop review of publications and reports, and consultation with the community and relevant experts. Information required at step three includes asset significance, threats, project goal, works and actions, time lags, effectiveness of works, private adoption of actions, delivery mechanisms, and costs. Using this information, apply the Public: Private Benefits Framework to help select policy mechanisms, and calculate a benefitcost ratio to be used in project ranking. The output from step three is a Project Assessment Report, which includes the benefit-cost ratio, risk factors (practice change, technical feasibility, socio-politics, long-term funding), spin-offs, quality of information, and key information gaps. 


\section{Step 4: Selection of priority projects}

Select a short list of priority assets/projects based on the information in the Project Assessment Report and other relevant considerations.

\section{Step 5: Investment plans or funding proposals}

Develop investment plans or proposals for external funding (depending on whether INFFER is being used to allocate an internal budget or to develop and assess projects for external funding).

\section{Step 6: Implementing funded projects}

Implement those projects that receive funding. In many cases, the first stage of a project should consist of a detailed feasibility investment, involving targeted collection of additional information to strengthen the assessment done in step three.

\section{Step 7: Monitoring, evaluation, and adaptive management}

Monitor, evaluate, and adaptively manage projects. After feasibility assessment, and at regular intervals thereafter (every two years, for example), the data in the original Project Assessment Form for each funded asset/project should be updated to reflect lessons learned, progress towards outcomes, and any new data or analysis that has become available. At this point, managers should consider whether the original design of the project is still suitable, and whether the project should remain a priority.

More information: www.inffer.com.au

\section{Conclusion}

These case studies highlight the important role that farmers play in protecting significant environmental assets at a range of scales. While these assets occur in the private land estate and on public land, it is the actions of farmers that have a principal impact on the achievement of public good outcomes. Achievement of these outcomes requires significant, long-term changes in land use and management, which come at considerable financial and social cost to farmers, and will not be adopted without the provision of adequate financial incentives in the form of stewardship payments.

In all three case studies, an assessment was made using INFFER, the Investment Framework for Environmental Resources (Pannell et al. 2011, and see Box 4.1), to assess the cost-effectiveness of different scenarios, and to support the choice of appropriate actions and policy interventions. Unsurprisingly, the detailed analysis supported by INFFER revealed that the actual cost of the described projects 
was far greater than originally anticipated, perhaps by an order of magnitude. The specification and analysis of SMART targets is crucial to understanding the scale of payments required to meet ecologically and socially meaningful results.

In both water quality projects examined, not only are the direct upfront costs considerably greater than could be accommodated through current state and Commonwealth environment programs, but there are also significant ongoing costs associated with maintaining benefits. The payment of ongoing stewardship costs, especially when linked to BMPs, is likely to be challenging and require improved scientific and technical understanding of the effectiveness of practices and a major shift in Australian NRM policy.

\section{References}

Australian Government (2014) Monitoring, evaluation, reporting and improvement tool (MERIT), Commonwealth of Australia, Canberra. Available at: www.nrm.gov.au/funding/merit/index.html.

Australian Government (2015) Australia's 15 National Biodiversity Hotspots, Commonwealth of Australia, Canberra. Available at: www.environment.gov.au/biodiversity/conservation/hotspots/ national-biodiversity-hotspots.

Beverly, C., A. Roberts, K. Stott, O. Vigiak and G. Doole (2013) 'Optimising economic and environmental outcomes: Water quality challenges in Corner Inlet Victoria', Proceedings of MODSIM 2013, Adelaide. Available at: www.mssanz.org.au/modsim2013.

Dickson, M., G. Park, and A. Roberts (2013) Corner Inlet Water Quality Improvement Plan, West Gippsland Catchment Management Authority, Traralgon, Victoria.

Doran, G.T. (1981) 'There's a S.M.A.R.T. way to write management's goals and objectives', Management Review 70(11): 35-6.

McDonald, G. and B. Roberts (2006) 'SMART water quality targets for Great Barrier Reef catchments', Australasian Journal of Environmental Management 13: 95-107. 
Pannell, D.J. (2008) 'Public benefits, private benefits, and policy intervention for land-use change for environmental benefits', Land Economics 84(2): 225-40.

Pannell, D.J., A.M. Roberts, G. Park, et al. (2011) 'Integrated assessment of public investment in land-use change to protect environmental assets in Australia', Land Use Policy 29: 377-87.

Park, G., A. Roberts, J. Alexander and D. Pannell (2013) 'The quality of resource condition targets in regional natural resource management in Australia', Australasian Journal of Environmental Management 20(4): 285-301. Available at: dx.doi.org/10.1080/144 86563.2013.764591.

Park, G., C. Beverly, A. Roberts and M. Dickson (2014) Bioeconomic modelling scenarios and results report: Milestone 3 - Burnett Mary Water Quality Improvement Plan. Available at: www.bmrg. org.au/files/4314/3700/8083/BE_Model_Scenarios_Final_report28Mayv6.pdf.

Roberts, A.M., D.J. Pannell, G. Doole and O. Vigiak (2012) Agricultural land management strategies to reduce phosphorus loads in the Gippsland Lakes, Australia', Agricultural Systems 106(1): 11-22.

Secretariat Reef Water Quality Plan Protection (2013) Reef Water Quality Protection Plan, Queensland Government. Available at: www.reefplan.qld.gov.au/resources/assets/reef-plan-2013.pdf. 
This text is taken from Learning from agri-environment schemes in Australia: Investing in biodiversity and other ecosystem services on farms, edited by Dean Ansell, Fiona Gibson and David Salt, published 2016 by ANU Press, The Australian National University, Canberra, Australia. 